\title{
Perceived Usefulness and Ease of Use of the Learning Management System as a Learning Tool
}

\author{
Jowati Juhary ${ }^{1}$ \\ ${ }^{1}$ Language Centre, National Defence University of Malaysia, Kuala Lumpur, Malaysia \\ Correspondence: Jowati Juhary, Language Centre, National Defence University of Malaysia, Sungai Besi Camp, \\ 57000 Kuala Lumpur, Malaysia. Tel: 603-9051-4447. E-mail: jowati@upnm.edu.my
}

Received: April 18, 2014 Accepted: May 20, 2014 Online Published: July 27, 2014

doi:10.5539/ies.v7n8p23 URL: http://dx.doi.org/10.5539/ies.v7n8p23

\begin{abstract}
A Learning Management System (LMS) can be a singularly critical platform to report on students' learning progress and to monitor students' learning engagement. At the only defence university in Malaysia, the National Defence University of Malaysia (NDUM) adopts the LMS as a supplementary learning and teaching tool. Nonetheless, the aspiration of Malaysia to ensure that higher learning institutions actively participate in the Massive Open Online Course (MOOC) has further emphasised the need for the NDUM to provide an effective LMS to the students. This paper aims at examining the perceptions of students at the Defence University on the use of the LMS. The Technology Acceptance Model (TAM) is used as the basis for generating hypotheses and conceptual framework for the paper. Five classes of students were involved in the data collection resulting in 100 returned questionnaires. Preliminary findings highlight students' positive attitudes towards the use of the LMS; however, there are technical issues that must be addressed to ensure that the LMS can function effectively.
\end{abstract}

Keywords: Defence University, LMS, MOOC, OCW, OER, TAM

\section{Introduction}

\subsection{The Challenges}

The National Defence University of Malaysia (NDUM) is the youngest public university in Malaysia. Being the youngest, the NDUM can learn from the experiences of other 19 public universities especially by benchmarking best practices for teaching and learning. The challenges are aplenty, but the critical ones include fulfilling the expectations of the Ministry of Education, Malaysia especially when it involves the use of digital technologies. At eight years old, the university has already purchased a Learning Management System (LMS) from a local private company in 2009. This was driven by two factors. Firstly, the National Higher Education Strategic Plan, launched in 2007, outlines 23 Critical Agenda Projects (CAPs) including e-learning. The importance of e-learning for tertiary education is based on these main strategic objectives (The National Higher Education Strategic Plan Beyond 2020, 2007),

1) Developing digital repository and directory that can be utilised by all tertiary education providers, thus ultimately encouraging the culture of sharing resources and e-content (electronic content)

2) Enculturation of e-learning at tertiary education providers in order to develop e-learning practitioners and garnishing authentic e-content

3) Conducting research and development in the e-learning pedagogy and technologies

Secondly, in order to provide directions for the practice of e-learning, the National e-Learning Policy was launched in April 2011. This move further heightens the need for all education providers to ensure that students at their respective universities are using e-learning, and ultimately the students are comfortable learning with technology (see Jonassen, Peck, \& Wilson, 1999).

The main question addressed in this paper is whether students at the Defence University are ready to change the way they learn. Earlier assumptions may suggest that the new breed of students today is keen to use technology because they are what scholars called Digital Natives (Prensky, 2010). Therefore, this paper has two important objectives,

1) To determine the acceptance level of the LMS by students 
2) To identify the factors that may hinder or influence the use of the LMS by students

\subsection{The Importance of the Study}

To achieve the national agenda for e-learning, each public university must be able to meet the targets of the assigned outcomes. For the year 2013 and 2014, the main Key Performance Indicator (KPI) for each public university is to have blended learning (or sometimes referred to as hybrid learning) for at least 50 percent of its courses. Therefore for the Defence University, about 163 of 325 courses offered in one academic session must have learning materials in the LMS. The operational definition adopted by the Defence University for this KPI is at least six learning materials including lecture notes, reading materials, teaching videos and assessments must be uploaded for the 163 courses.

The achievement for the NDUM for the year 2013 was 18.6 percent which is equivalent to about 60 courses that had uploaded materials on the LMS. Upon looking at this achievement, the main question that must be addressed is what hinders academic staff or students from utilising the LMS. Therefore, as a preliminary study, this paper is to examine the students' attitudes towards the LMS. Other factors that contribute to the failure or success of the LMS are not covered in this paper. Future research will report on these. To further understand the importance of this research, the next sub section will explain selected literature on e-learning platforms and the conceptual framework of this paper.

\subsection{Relevant Literature}

Dalsgaard (2006) suggested that the integration of significant elements for teaching and learning is made possible by the LMSs. The LMS expedites course management and gives students the benefits of using e-content as supplementary tools for learning. At the beginning of the introduction of the LMS, many higher education providers were doubtful about the LMS as a tool to assist classroom and/or independent learning. Benson and Palaskas (2006) put forth several issues including governance, management and technical supports and professional development of instructors.

\subsubsection{The Pioneers}

There are two popular licensed LMSs. The first one is WebCT, created by a university instructor at the University of British Columbia. WebCT uses a "standard Web-based shell or learning management system" (Bates \& Sangra, 2011). WebCT can perform several key functions such as the ability to integrate spaces for learning objectives, to develop content, to upload documents and to test students using its assessment tools. In Malaysia, Universiti Teknologi Malaysia used to have WebCT as its LMS. Nevertheless, expensive licensing and maintenance had been the major reasons why the university opted for a free LMS, Moodle in 2004.

The second one is Blackboard, which actually bought WebCT. Blackboard was established in 1997 by Pittinsky and Chasen. According to Bradford, Porceillo, Balkon and Backus (2007), more than 70 percent of colleges in the United States use Blackboard as their LMSs. Moreover, two higher learning institutions in Malaysia use Blackboard as their LMSs. One is a public university, Universiti Tun Hussein Onn, and the other is a private university, Sunway University College (Embi, 2011). It appears that out of 20 public universities and hundreds of private institutions in Malaysia, only these two are using Blackboard. The number is small, and the author argues that perhaps the high cost to purchase and maintain is the reason why Blackboard is unpopular in Malaysia.

Therefore, most higher learning institutions shift and/or opt for open source which is free such as Moodle as further explained in the next sub paragraph.

\subsubsection{Moodle}

Moodle was developed by an Australian graduate student in 1999. It is fast becoming a dynamic LMS in many countries including Malaysia. Out of 20 public universities in Malaysia, Embi (2011) reported that nine universities adopt Moodle as their LMSs. In fact, since its release to the public in 2002, Moodle has become the prominent open source in North American and European universities (Itmazi \& Megias, nd). A white paper on Open Source LMS suggested that at the end of 2010, there were about 49,600 registered sites that utilised Moodle, and these sites offered 4 million courses to about 38 million users worldwide (Open Source Learning Management System: Moodle and Sakai, 2010). There are several key factors that contribute to this. Firstly, the education providers do not need to pay anything in order to use Moodle. Secondly, other than its free nature, Moodle is able to attract many users because of other aspects explained next. It is argued that Moodle is much more interactive than Blackboard (Beatty \& Ulasewicz, 2007). Furthermore, Moodle is used as a supplementary learning tool for courses that are offered online. Martin-Blas and Serrano-Fernandez (2009) argued that Moodle can help to strengthen students' abilities and knowledge. They further established that Moodle is the best 
platform for instructors to "organise, manage and deliver contents."

\subsubsection{The LMS at the Defence University}

The NDUM purchased its LMS called 'My Online Classroom' from a local vendor. It uses WebCube technology that enables customised menus of the system according to the requirements of the Defence University. The LMS is able to conduct online teaching and learning as well as online assessments and discussions through its forum page. The LMS can actually simplify the process of compiling notes and learning materials since it is able to accept source codes (to be embedded in the portal) from various e-content development tools or Web 2.0 technologies such as YouTube, Presentme and Blendspace. This allows teaching staff the freedom to reuse and recycle teaching materials that are available free online without having to start from scratch. Figures 1 and 2 illustrate the first page of the LMS and the layout of the online notes.

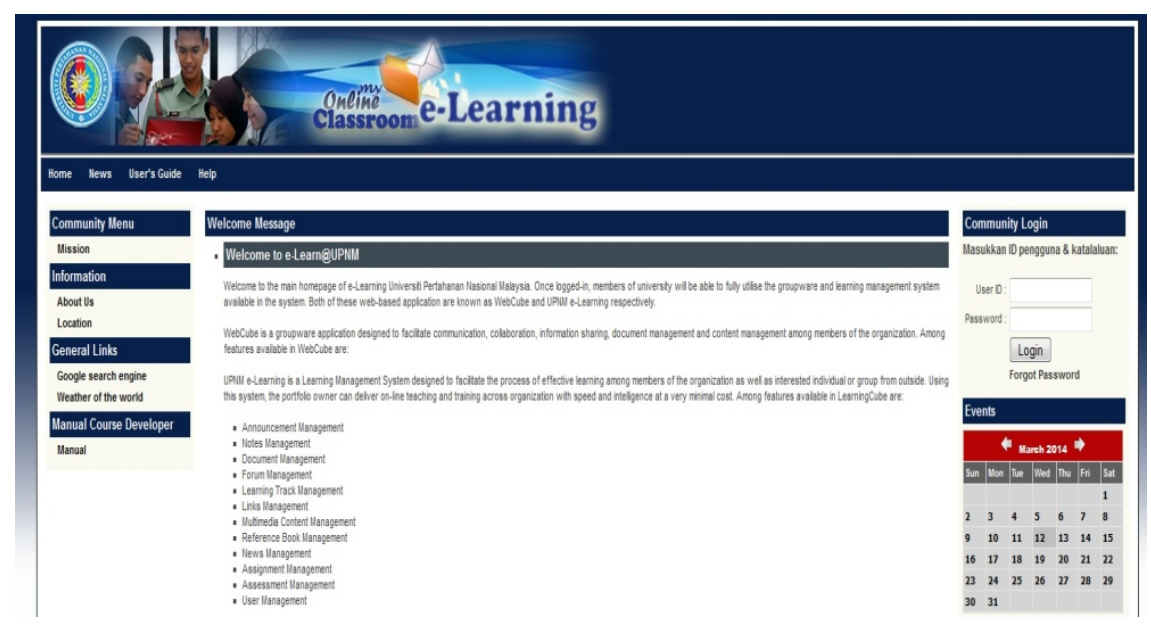

Figure 1. The first page of the LMS

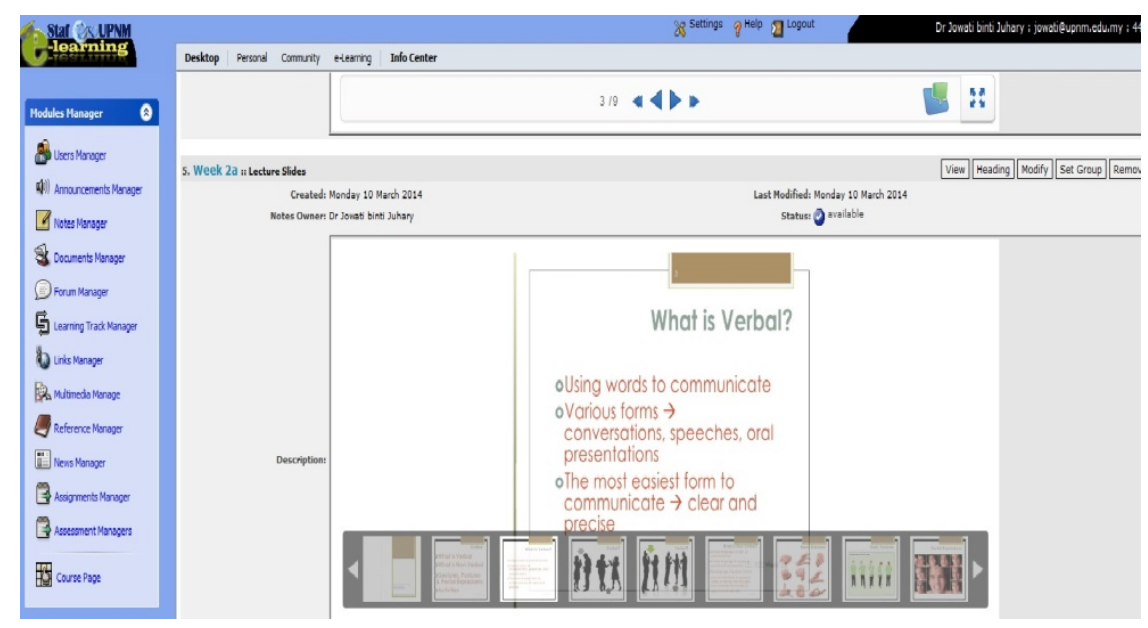

Figure 2. The online notes (through the author's portal)

All registered students at the NDUM, from the foundation year to the post graduate level, are able to log in the LMS. Based on the academic semesters, students will be able to view, use and participate in the courses that they are enrolled in during a particular semester, provided that the lecturers upload the materials. The LMS too can become a one stop centre for the students to access relevant announcements about their courses, to collect notes or simply to read their learning materials online. 


\subsubsection{OER, OCW and MOOC}

The democratisation of education has strengthened the need for education providers to expand their services to anyone regardless of the locations. Various movements are actively promoting equality in education. First coined in 2002, Open Educational Resources (OER) movement allows those who are in quest of knowledge to benefit from learning materials and contents freely available online. The aim of OER is to provide more equal access to knowledge and educational opportunities (Lim, 2011). What OER offers are educational materials that are made "freely and legally available on the Internet for anyone to reuse, revise, remix and redistribute" (White Paper: Open Educational Resources: Breaking the Lockbox on Education, 2013). Some useful OER sites are Open Courseware Consortium, MIT; Carnegie Mellon Open Learning Initiative and OpenLearn, OUUK. One Malaysian university has also established its OER initiative, Universiti Teknologi Malaysia at ocw.utm.my.

Consequently, providers of contents and learning materials are not only disseminating knowledge but they are also offering free courses online to the general public. The free courses and materials can be used by other academics and students alike as academics can place the links of the OER in the LMS, and students can also explore various learning materials elsewhere.

There are various types of OER, and one of them is Open Courseware (OCW). OCW could be defined as learning materials that are organised as complete courses including the assessments. According to Caswell (2009), OCW has several institutional benefits such as showcasing the institution educational quality, connecting to students before, during and after enrolment and promoting the researchers and faculties' intellectual works.

The acceptance and usefulness of OER and OCW have led to another buzz concept, Massive Open Online Course (MOOC). MOOC emerged from OER movements, coined by Dave Cornier and Bryan Alexander. Since its inception in 2008, MOOC becomes an alternative platform for online learning rapidly. This can be seen in many instances where tertiary education providers started to inaugurate their MOOC initiatives. For example, in 2013, Taylor's University, Malaysia began to offer courses through MOOC. Recently, another university, Universiti Putra Malaysia has also launched its MOOC initiative called PutraMOOC in April 2014.

Regardless of the critiques on MOOC (see Delbanco, 2013; Gans, 2014), this latest development has sparked the interest and determination of the Ministry of Education, Malaysia in MOOC. In their monthly speeches to the representatives of the universities, and during various meetings and gatherings at the ministerial level, the Minister of Education II, Malaysia and the Secretary General II of the Ministry have put a great emphasis on the involvement of Malaysian tertiary education providers in MOOC. In fact, by 2015, 13 selected public universities will need to upload the e-content of their courses to a local MOOC platform to be developed and operated by MIMOS, a research centre for Information Communication Technology under the purview of the Ministry of Science, Technology and Innovation, Malaysia. What this means is that the government is adamant about the use of not only digital technologies but also the concept of resource sharing and content development.

\subsubsection{The Conceptual Framework}

Meanwhile, the conceptual framework of this paper adopts Davis, Bagozzi and Warshaw's Technology Acceptance Model (TAM) (see Figure 3). The model suggests that user perceptions of usefulness and ease of use determine attitudes towards using an online tool. According to the TAM, behavioural intentions to use an online tool in turn determine the actual system use. This model then allows the author to gauge the success or failure of the LMS as an online support tool for learning. Scholars found the model to be effective for investigating technology acceptance and have been using it for different tasks and tools (see Morris \& Dillion, 1997; Schroff, Deneen, \& Ng, 2011; Aypay, Celik, Aypay, \& Sever, 2012). Further, Teo (2011) argued in his study that perceived usefulness of technology became the strongest factor that influences the intentions of users to adopt technology. Moreover, Wu (1999) also suggested that the model is able to gauge the relationship in advertising between perceived interactivity and attitudes towards websites. Thus, the author opines that this study too could generate conclusive findings on the students' acceptance of the LMS at the Defence University. 


\subsection{Hypotheses}

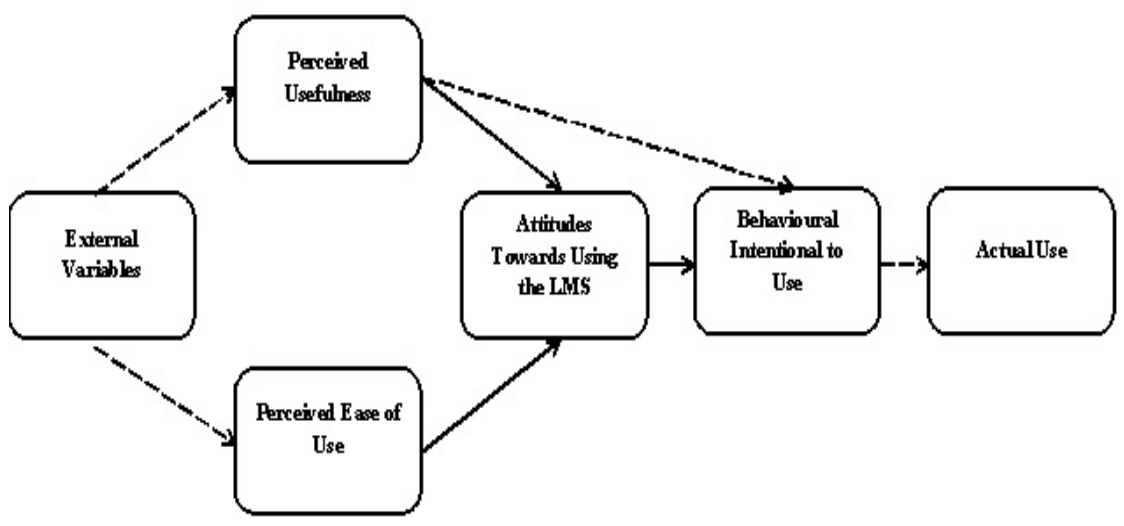

Figure 3. The conceptual framework (adopted from Davis et al., 1989)

(This study only focuses on the relationships drawn in solid lines)

After five years, the LMS is a critical indicator of students' autonomy in learning. As an online support system, students can study anywhere and at any time. Therefore, it is assumed that students can rely on the LMS to assist them in learning, during and after formal classes. Specifically, the detailed hypotheses, based on the conceptual framework are,

H1: Perceived usefulness will have a significant influence on attitude towards using the LMS.

H2: Perceived ease of use will have a significant influence on attitude towards using the LMS.

H3: Attitude towards usage will have a significant influence on users' behavioural intentions of using the LMS.

\section{Method}

This paper relied heavily on quantitative data collected by means of surveys. There were basically two main phases. Generally, the first phase focused on finding relevant literature review for this paper. At the same time, the hypotheses and objectives were refined in order to ensure successful completion of this paper. Items in the questionnaire too were developed and redesigned to suit the respondents' understanding of the LMS. The questionnaire was adopted from Nasser, Cherif, and Romanowski (2011). The second phase concentrated on the technicalities of data collection such as sample population. The number of student respondents was determined by the number of students the author had in Semester 1, Academic Session 2013/2014. Following the data collection, data analysis using the Statistical Package for Social Sciences (SPSS) Version 18 and writing up of this paper were done by comparing and contrasting all the data gathered. The next sub sections further explain the procedures of data collection.

\subsection{Data Collection Methods}

Five classes were involved in the data collection process. The data were collected during Semester 1, Academic Session 2013/2014 which ran from September 2013 to January 2014. There were 14 weeks of lectures and tutorials, and all students were asked to answer the questionnaires in Week 14. There were originally 128 questionnaires distributed to students, but only 100 copies were returned.

\subsection{Participants (Subject) Characteristics}

There were 28 second year students and 100 first year students who became the respondents for this paper. The second year students were taking Oral Communication course, and the first year students were taking two different courses. 52 first year students were in the Academic Writing course (two groups) and 48 were in Basic Grammar and Vocabulary classes (two groups). Of this number, 31 were ladies and 97 gentlemen. In terms of categories of students, only 18 were civilians and the rest were military cadets. The NDUM is a residential campus, and this permits the military cadets to undergo their academic session and military training concurrently. Further, the Defence University is a boutique university, thus allowing only 5,000 students at a time.

\subsection{Sampling Procedures}

As described earlier, the total number of students in the author's classes was only 128 , and automatically they 
were chosen as the subjects of this paper. The total number of students taking all three courses of English in that semester was 1,178 with 361 students in Basic Grammar and Vocabulary classes, 433 in Academic Writing classes and 384 in Oral Communication classes. In general, only about nine percent of the students' population (who took English courses) was involved in this study.

\subsubsection{Limitation of the Sample Size}

Although the number of respondents was relatively small, the author has no control over it because she was only given five English classes. She could also have asked other instructors to participate in the study, but she opined that as a preliminary paper, the number of respondents is adequate. At the same time, she observed that the number of lecturers who actively utilised the LMS was almost none, thus limiting her resources to get more respondents for this study.

\subsubsection{Research Design}

The subjects underwent all 14 weeks of lectures, tutorials and online activities. Online materials uploaded included lecture slides, reading materials, video clips, quizzes, and students were also expected to participate in the online forums. Based on the TAM, students were observed on their attitudes towards using the LMS. Further, they were encouraged to log in the LMS at least once a week in order to familiarise them with the system and new ways of learning.

\section{Results}

This section is divided into two. The first looks at the descriptive statistics of the data presented in tables. Basic understanding of the scenario could be gathered in this sub section. The second sub section explores the significance of selected variables in the attempt to test the hypotheses of this paper.

\subsection{Descriptive Statistics}

This sub section presents the descriptive statistics of data based on the parts of the questionnaire. The questionnaire has four parts. The first part sought to understand students' perceptions of the Computer and Internet. The second part asked questions on the LMS. Nonetheless, for students who have never log in or use the LMS, they could skip this part. The third part elicits the respondents' opinions on issues related to the LMS, and the last part required students to offer comments on the use of the LMS or other matters related to technology and teaching and learning. It needs to be emphasised that the questionnaire uses a 4-point Likert scales ( 1 for Often, 2 for Sometimes, 3 for Rarely and 4 for Never for Parts A and B; and 1 for Strongly Agree, 2 for Agree, 3 for Disagree and 4 for Strongly Disagree for Part C).

Table 1. Descriptive statistics for Part A of the questionnaire

\begin{tabular}{lccc}
\hline & $\mathrm{N}$ & Mean & Std. Deviation \\
\hline Use Computer for Homework & 100 & 1.81 & .837 \\
Use the Internet for Homework & 100 & 1.64 & .785 \\
Communicate Through Email & 100 & 2.41 & .933 \\
Participate in Chats on the Internet & 100 & 2.21 & .977 \\
Find information on the Internet & 100 & 1.35 & .626 \\
Upload files on the Internet & 100 & 2.21 & .957 \\
Make Power Point Slides & 100 & 1.95 & .869 \\
\hline
\end{tabular}

Table 1 suggests that respondents were mostly engaged in academic activities including research work and assignments. This can be seen by the mean scores of computers and the Internet that are used for homework (1.81 and 1.64), mean score of using the Internet for research work (1.35) and mean score of using the computer to prepare slide presentations (1.95). Nonetheless, it is perplexing that respondents were not fond of using emails to communicate (2.41 and a standard deviation of .933 which suggests that respondents' options were scattered throughout all four scales). Perhaps, the respondents preferred to use other social media for communication such as Facebook or Twitter. 
Table 2. Descriptive statistics for Part B of the questionnaire

\begin{tabular}{lccc}
\hline & $\mathrm{N}$ & Mean & Std. Deviation \\
\hline Group Projects & 58 & 2.41 & .879 \\
Research & 58 & 2.29 & 1.556 \\
Homework & 58 & 2.14 & .805 \\
Communicate with lecturers & 58 & 2.67 & .846 \\
Extra Reading Materials & 58 & 2.17 & .861 \\
Lecture Slides & 58 & 1.95 & .847 \\
Online Quizzes & 58 & 2.05 & .847 \\
Forum & 58 & 2.62 & .970 \\
\hline
\end{tabular}

From Table 2, it can be concluded that only 58 respondents had used or logged in into the LMS. From the statistics, most respondents used the LMS for reading or downloading the lecture slides (1.95) as well as completing their homework, 2.14 and to collect extra notes for reading (2.17). The least useful function in the LMS appeared to be the Forum with a mean score of 2.62. The reason for this could be similar to the one on students' preference not to use email to communicate.

Table 3. Descriptive statistics for Part $\mathrm{C}$ of the questionnaire

\begin{tabular}{lccc}
\hline & $\mathrm{N}$ & Mean & Std. Deviation \\
\hline I do not know how to use the LMS & 100 & 2.57 & .891 \\
The LMS is too hard to use & 100 & 2.57 & .832 \\
I do not have computing facilities & 100 & 2.93 & .868 \\
I will not use the LMS without the instructions of my lecturers & 100 & 2.27 & .815 \\
I always have the Internet access to use the LMS & 100 & 2.71 & .967 \\
The loading time for materials is too long & 100 & 2.05 & .833 \\
The content of the LMS is not helpful & 100 & 2.94 & .708 \\
The Internet service is problematic & 100 & 2.07 & .998 \\
The LMS is user friendly & 100 & 2.35 & .716 \\
I have problems logging in the LMS & 100 & 2.28 & .986 \\
I am not interested to use the LMS & 100 & 2.89 & .665 \\
\hline
\end{tabular}

Table 3 reveals two important perspectives of the respondents. Firstly, respondents were actually interested to use the LMS as supported by the mean score of 2.89. Similar trends are observed for the other two highest mean scores. The respondents felt that the content of the LMS is helpful (2.94), and that they have adequate computing facilities (2.93). Secondly, the LMS has three technical concerns including the loading time, the Internet access and the $\log$ in access as supported by the mean scores of $2.05,2.07$ and 2.28 respectively. 
Table 4. Descriptive statistics for Part D of the questionnaire

\begin{tabular}{lcc}
\hline & Frequency & Percent \\
\hline Positive about the LMS & 12 & 12.0 \\
Internet problems - slow, crash, cannot access & 44 & 44.0 \\
Positive with minor improvements & 15 & 15.0 \\
Students need to be informed of the LMS & 6 & 6.0 \\
No Comments & 23 & 23.0 \\
\hline $\mathrm{N}=100$ &
\end{tabular}

Table 4 illustrates the opinions expressed by the respondents on the LMS. In general, 23 respondents out of 100 did not offer any additional comments on the LMS. Interestingly, six respondents felt that students need to be made aware of the LMS. The majority of the respondents linked their reluctance to use the LMS to the Internet problems including slow access or failure to get access, and some of them commented that at time, the LMS crashed in the middle of retrieving or downloading materials.

\subsection{Testing the Hypotheses}

Before the statistical analysis is presented, Table 5 illustrates the analytical tool used to test each hypothesis of this paper. This allows better understanding of how the analysis is generated, and facilitates the following analysis and discussion on these findings. Pearson Correlation was suitable for this paper because it explores the relationships between mixed variables that are present in the data.

Table 5. Hypotheses and data analysis

\begin{tabular}{lc}
\hline \multicolumn{1}{c}{ Hypotheses } & $\begin{array}{c}\text { SPSS } \\
\text { Analysis }\end{array}$ \\
\hline $\begin{array}{l}\text { H1: Perceived usefulness will have a significant } \\
\text { influence on attitude towards using the LMS. }\end{array}$ & $\begin{array}{l}\text { Correlations } \\
\text { (Pearson } \\
\text { H2: Perceived ease of use will have a significant } \\
\text { influence on attitude towards using the LMS. }\end{array}$ \\
$\begin{array}{l}\text { Correlation) } \\
\text { H3: Attitude towards usage will have a significant } \\
\text { influence on users' behavioural intentions of using } \\
\text { the LMS. }\end{array}$ \\
\hline
\end{tabular}

Table 6. Perceived usefulness of the LMS

\begin{tabular}{lcccccccc}
\hline & 1 & 2 & 3 & 4 & 5 & 6 & 7 & 8 \\
\hline Group Projects (1) & 1 & $.423^{* *}$ & $.315^{*}$ & $.445^{* *}$ & $.437^{* *}$ & $.406^{* *}$ & $.419^{* *}$ & $.516^{* *}$ \\
Research (2) & & 1 & .037 & .034 & $.263^{*}$ & .012 & $.295^{*}$ & .249 \\
Homework (3) & & & 1 & $.325^{*}$ & $.649^{* *}$ & $.526^{* *}$ & $.273^{*}$ & $.428^{* *}$ \\
Communicate with lecturers (4) & & & 1 & $.344^{* *}$ & $.270^{*}$ & .122 & $.423^{* *}$ \\
Extra Reading Materials (5) & & & & & 1 & $.566^{* *}$ & $.349^{* *}$ & $.353^{* *}$ \\
Lecture Slides (6) & & & & & & 1 & $.469^{* *}$ & $.510^{* *}$ \\
Online Quizzes (7) & & & & & & 1 & $.516^{* *}$ \\
Forum (8) & & & & & & & 1 \\
\hline
\end{tabular}

**. Correlation is significant at the 0.01 level (2-tailed).

*. Correlation is significant at the 0.05 level (2-tailed).

$\mathrm{N}=58$ (those who had used the LMS) 
Table 7. Perceived ease of use of the LMS

\begin{tabular}{llccc}
\hline & 1 & 2 & 3 & 4 \\
\hline The LMS is too hard to use & 1 & $.323^{* *}$ & $.321^{* *}$ & $.256^{*}$
\end{tabular}

(1)

The loading time for materials is too long (2)

I have problems logging in the LMS (3)

The Internet service is

$1 \quad .216^{*} \quad .372^{* *}$

problematic (4)

**. Correlation is significant at the 0.01 level (2-tailed).

*. Correlation is significant at the 0.05 level (2-tailed).

$\mathrm{N}=100$ (all respondents).

Table 8. Attitudes towards the LMS and behavioural intentions

\begin{tabular}{lcc}
\hline & 1 & 2 \\
\hline I am not interested to use the LMS (1) & 1 & $.205^{*}$ \\
I will not use without the instructions of & & 1 \\
my lecturers (2) & & \\
\hline
\end{tabular}

*. Correlation is significant at the 0.05 level (2-tailed).

$\mathrm{N}=100$ (all respondents).

What can be discerned from Tables 6,7 and 8 is that the hypotheses are modestly supported because in general students' perceived usefulness and ease of use had influenced students' attitudes towards the LMS ( $<.01$ and $\mathrm{p}<.05,2$-tailed). Further, respondents' attitudes too had influenced the respondents' behavioural intention towards using the LMS. These three tables also suggest that respondents with positive perceived usefulness and ease of use had positive attitudes towards using the LMS. Because of these attitudes, they ultimately had behavioural intentions to use the LMS. This can be seen from Table 8 where the correlation test illustrates that respondents' interest to use the LMS and their attitudes to use the LMS voluntarily have resulted in, albeit, a weak correlation $(\mathrm{r}=.205, \mathrm{p}<.05)$. In actual fact, the correlations for most of the variables are found to be between modest and weak, with the best correlation coefficient of .649. A detailed discussion on these findings will be presented next.

\section{Discussion}

Based on the findings presented in tables above, the author opines that the respondents are positive about the use of the LMS. Nonetheless, they are also discouraged by several aspects of the implementation or execution of the LMS at the Defence University. This discussion will then revolve around the two objectives presented earlier in this paper. In so doing, the objectives of the paper will be fulfilled and achieved.

\subsection{Objective 1-To Determine the Acceptance Level of the LMS by Students}

The author argues that this objective is achieved based on the findings presented before. In general, the acceptance level ranges from 3 to 4 on a scale of 5 . The majority of the respondents perceived the LMS positively. They were interested to use the LMS, and they felt that the content of the LMS is helpful (mean scores of 2.89 and 2.94 respectively). This positive acceptance is further supported by the respondents' engagement with the LMS for academic activities such as research work and assignment. Although not every respondent had actually used the LMS, the 58 respondents who had had the experience of using the LMS also concurred in the positive acceptance of the LMS. These respondents put forward that the LMS is mainly used for academic works including collecting notes as well as reading lecture slides.

The general comments given by the respondents also supported their acceptance of the LMS. Table 4 illustrates their positive attitudes towards the LMS. 27 respondents were positive about the LMS; 15 of these respondents 
opined that the LMS needs some minor improvements. By this remark, the author argues that perhaps this refers to the technical issues that will be discussed in the next sub section. Meanwhile, 44 respondents were more focused on the problems of using the LMS where they commented that the Internet access/LMS is slow, the LMS sometimes crashes and the LMS occasionally cannot be accessed. Although it appears that the majority of the respondents had hesitation to use the LMS, the author argues that this shows their interests to use the LMS, and because of this interest, they took the time to use the LMS and provided some constructive comments for future improvement.

\subsection{Objective 2-To Identify the Factors That May Hinder or Influence the Use of the LMS by Students}

This objective is also achieved. In general, there are three technical issues that may have hindered the respondents to use the LMS. Perhaps, these issues too have contributed to the small number of respondents who had actually used the LMS, which is only 58. Firstly, the loading time of the materials to be viewed or downloaded becomes the most critical factor. At a mean score of 2.05, the loading time refers to the time taken for the respondents to get the complete display of the materials in the LMS, or to be able to download the materials from the LMS. Secondly, the Internet access becomes another factor that may hinder students' perceived usefulness of the LMS. The access refers to the ability of the respondents to use the LMS on a networked or Wi-Fi access on campus or off campus. Thirdly, some respondents were not able to log in the LMS due to various reasons. Failure to $\log$ in could be categorised into two: failure to log in for first time users and failure to $\log$ in at any particular time.

The factors are also better supported by Table 4 when 44 respondents suggested various reasons for their concerns about the LMS. Although the author is not able to justify the technical difficulties faced by the students, the LMS may become a burden to the students in their learning process should the problems remain unsolved. As a tool to help students learn anywhere and at any time, the LMS has huge potential to assist students who may not be able to grasp concepts during the face-to-face sessions with their instructors.

\subsection{Recommendations}

According to Bates and Sangra (2011), technology is the key factor for ensuring relevant and necessary change in higher education transformation. The NDUM must be ready to also transform its ways of teaching and learning processes. One of the ways is by adopting the use of its LMS to the fullest. Based on the factors that can hinder students' engagement with the LMS, the author argues that the Information Communication and Technology Centre should not be shouldering the responsibilities alone. Rather, good and efficient access requires financial support from the university. Therefore, the top management must believe in the LMS in order to help students learn. Only through this 'buy in' concept, the NDUM as a whole can start to use the LMS effectively. Further, all heads of departments and deans must be made fully aware of the LMS as one of the tools for students' learning activities. As it is at the NDUM currently, the awareness level of the LMS is rather low. In fact, six respondents felt that the student population should be informed of the LMS. Thus, perhaps the top management, heads of departments and the rest of the academics should also be informed of the LMS.

To conclude, although this paper only has 100 respondents, the findings may reflect the perceived usefulness and ease of use of the LMS at the NDUM. Future research will have to consider using all students of the NDUM, and this can only be done when more instructors are using the LMS constantly and consistently. At this stage, the author is trying her best to encourage the staff at her department to use the LMS by highlighting the importance of giving students various options for learning. The LMS can become the best venue for flipping classroom practice (see Tucker, 2012) where focus in the classroom will now shift to discussions on difficult concepts of the lessons. Although at the NDUM face-to-face sessions will always be the main delivery mode for teaching and learning, the LMS can also be used during these sessions. In so doing, the national agenda for e-learning will be realised.

\section{Acknowledgements}

The author thanks her students who were involved as survey respondents for this paper.

\section{References}

Aypay, A., Celik, H. C., Aypay, A., \& Sever, M. (2012). Technology Acceptance in Education: A Study of Pre-Service Teachers in Turkey. The Turkish Online Journal of Educational Technology, 11(4), 264-272.

Bates, A. W., \& Sangra, A. (2011). Managing Technology in Higher Education. New Jersey: Jossey-Bass.

Beatty, B., \& Ulasewicz, C. (2007). Online Teaching and Learning Transition: Faculty Perspectives on Moving from Blackboard to Moodle Learning Management System. TechTrend, 50(4), 36-45. 
http://dx.doi.org/10.1007/s11528-006-0036-y.

Benson, R., \& Palaskas, T. (2006). Introducing a New Learning Management System: An Institutional Case Study. Australasian Journal of Educational Technology, 22(4), 548-567.

Bradford, P., Porceillo, M., Balkon, N., \& Backus, D. (2007). The Blackboard Learning System. The Journal of Educational Technology System, 35, 301-314. http://dx.doi.org/10.2190/X137-X73L-5261-5656

Caswell, T. (2009). Understanding OER and OCW. Open Courseware Consortium. Retrieved from $\mathrm{http}: / /$ tomcaswell.com/consulting

Dalsgaard, C. (2006). Social software: E-learning beyond learning management systems. European Journal of Open Distance and e-Learning, 2.

Davis, F. D., Bagozzi, R. P., \& Warshaw, P. R. (1989). User Acceptance of Computer Technology: A Comparison of Two Theoretical Models. Management Science, 35(8), 982-1003. http://dx.doi.org/10.1287/mnsc.35.8.982.

Delbanco, A. (2013). MOOCs of Hazard. New Republic. Retrieved March 10, 2014, from http://www.newrepublic.com//article/112731/moocs-will-online-education-ruin-university-experience

Embi, M. A. (2011). E-Learning in Malaysian Higher Education Institutions: Status, Trends and Challenges. Kuala Lumpur: Ministry of Higher Education Malaysia.

Gans, J. (2014). Will MOOCs lead to the democratisation of education? Online Education. Retrieved March 10, 2014, from http://www.digitopoly.org/category/online-education/

Itmazi, J. A., \& Megias, M. G. (unpublished). Survey: Comparison and Evaluation Studies of Learning Content Management Systems.

Jonassen, D., Peck, K., \& Wilson, B. (1999). Learning With Technology: A Constructivist Perspective. Upper Saddle River, NJ: Prentice Hall.

Lim, T. (2011). Open Educational Resources. A presentation at a Seminar for the Open University Malaysia, Kuala Lumpur, Malaysia.

Martin-Blas, T., \& Serrano-Fernandez, A. (2009). The Role of New Technologies in the Learning Process: Moodle as a Teaching Tool in Physics. Computers and Education, 52, 35-44. http://dx.doi.org/10.1016/j.compedu.2008.06.005.

Morris, M., \& Dillon, A. (1997). How User Perceptions Influence Software Use. IEEE Software, 14(4), 58-65. http://dx.doi.org/10.1109/52.595956.

Nasser, R., Cherif, M., \& Romanowski, M. (2011). Factors that Impact Student Usage of the Learning Management System in Qatari Schools. The International Review of Research in Open and Distance Learning, 12(6), 39-62.

Open Source Learning Management System: Moodle and Sakai. (2010). A White Paper. Santa Cruz: Monarch Media Inc.

Prensky, M. (2010). Teaching Digital Natives. California: Corwin.

Schroff, R. H., Deneen, C. C., \& Ng, E. M. W. (2011). Analysis of the technology acceptance model in examining students' behavioural intention to use an e-portfolio system. Australasian Journal of Educational Technology, 27(4), 600-618.

Teo, T. (2011). Technology Acceptance in Education: Research and Issues. Rotterdam: Sense Publishers. http://dx.doi.org/10.1007/978-94-6091-487-4.

The National Higher Education Strategic Plan Beyond 2020. (2007). Putrajaya: Ministry of Higher Education Malaysia.

Tucker, B. (2012). The flipped classroom: Online instruction at home frees class time for learning. Education Next, Winter, 82-83.

White Paper: Open Educational Resources: Breaking the Lockbox on Education. (2013). The William and Flora Hewlett Foundation.

Wu, G. (1999). Perceived Interactivity and Attitude towards Websites. A presentation at the 1999 Annual Conference of American Academy of Advertising, Albuquerque, New Mexico. 


\section{Copyrights}

Copyright for this article is retained by the author(s), with first publication rights granted to the journal.

This is an open-access article distributed under the terms and conditions of the Creative Commons Attribution license (http://creativecommons.org/licenses/by/3.0/). 